\title{
Would the association of different Therapeutic Agents be the Best Solution for the Treatment of Nocturnal Enuresis?
}

\author{
Mariane Ritter wodiani², Taís Rodrigues Gasparini ${ }^{3}$, Karine Furtado Meyer ${ }^{4}$ and Luiz g Freitas Filho ${ }^{1 *}$ \\ ${ }^{1}$ Department of Surgery, Universidade Federal De São Paulo, Fundação Universidade Regional de Blumenau \\ ${ }^{2}$ Medical Student, Fundação Universitária Regional de Blumenau, Brazil \\ ${ }^{3}$ Medical Student, Fundação Universitária Regional de Blumenau, Brazil \\ ${ }^{4}$ Consultant in Pediatric Urology, Federal University of São Paulo and Fundação Universitária Regional de Blumenau, Brazil
}

Submission: December 05, 2018; Published: January 23, 2019

*Corresponding author: Luiz G Freitas Filho, Rua Batista Cepelos, 87 - ap 61, 04109-120 São Paulo, Brazil.

\begin{abstract}
Introduction: We compare the efficacy of urological physiotherapy and parasacral neuromodulation and biofeedback in combination with the use of oxybutynin in the treatment of enuresis. Nocturnal enuresis is defined as the involuntary leak of urine that occurs during sleep. There are three pathogenic mechanisms responsible for the condition: nocturnal polyuria; overactivity of the detrusor; and high arousal threshold; all of which caused by a likely alteration in the control of the pontine micturition reflex center.

Materials and Methods: Eighty-two (82) children of both genders with a nocturnal enuresis diagnosis were selected, ages ranging between 5 and 14 years, in the period from January to July 2017. The children were separated into two groups: Group 1: taking $0.2 \mathrm{mg} / \mathrm{kg}$ oxybutynin every 12 hours. Group 2: taking $0.2 \mathrm{mg} / \mathrm{kg}$ oxybutynin every 12 hours + urological physiotherapy with neuromodulation and biofeedback. The results were evaluated according to the International Children's Continence Society (ICCS) standardization. For statistical analysis the continuous variables were assessed by the Qui-square test. Fisher's exact test was used to compare categorical data. The results were considered significant for $\mathrm{p}<0.05$.
\end{abstract}

Results: The children undertaking the physiotherapy and oxybutynin treatment fared better as compared to the ones taking the drug alone.

Conclusion: The cure rate and partial improvement were higher in patients undergoing the combination of physiotherapy with biofeedback and parasacral stimulation plus the use of oxybutynin as compared to the patients in the group taking oxybutynin alone.

Keywords: Nocturnal enuresis; Overactive bladder; Transcutaneous electric nerve stimulation; Biofeedback; Oxybutynin

\section{Introduction}

Urinary incontinence is defined as the involuntary leak of urine according to the International Continence Society terminology [1]. When involuntary leak of urine occurs during sleep the term enuresis is used and when it occurs at night, it is referred to as nocturnal enuresis [2]. The prevalence of nocturnal enuresis is estimated at about $10 \%$ for 7 -year-old children; however, in $2 \%$ to $3 \%$ it may persist into adulthood [3]. The involuntary leak of urine during sleep is considered normal during the child's development and should be investigated if surpassing the age of five years [4]. Nocturnal enuresis can be classified as primary enuresis, when the patient has never had sphincter control, or as secondary enuresis, when the child, following a period of micturition control, again starts presenting urinary leak episodes during the night. As for the symptoms, enuresis can be divided into monosymptomatic, when the only symptom is bedwetting while asleep, or nonmonosymptomatic, when the nocturnal leak is associated with other lower urinary tract symptoms, such as urgency or greater urinary frequency [5].

Currently three are the pathogenic mechanisms accepted as possibly responsible for the condition: nocturnal polyuria that may or may not be connected with a high fluid intake; detrusor muscle overactivity; and high arousal threshold; all of which caused by a likely alteration in the control of the pontine micturition reflex center [6]. It seems evident that there are enuretic children that produce unusually large amounts of urine at night; such polyuria is usually explained by the smaller production of the vasopressin hormone during the night period [7]. It is also known that bedwetting, in some non-bedwetting children, can be caused by high fluid intake at night [8]. 
Many children, however, wet their bed not because their bladder is full but rather because they have nocturnal overactivity of the detrusor muscle. An indirect evidence of the problem is the existence of a relevant number of children that have urge incontinence and urinary urgency; there is also the fact that enuretic children, the nonpolyuric ones in particular, produce smaller volumes of urine than non-bedwetting children $[9,10]$.

Bedwetting children can be described as "deep sleepers", which can be corroborated by the fact that their parents always refer to them as "hard to be woken up", and also by studies showing an objective increase in the arousal threshold to trigger the micturition [11]. There is growing evidence that the same child may present the three mechanisms (polyuria, overactivity of the detrusor, high arousal threshold) either alone or combined. Thus, those children would most likely have a disorder in the "Lócus Coeruleus" (LC), a group of noradrenergic neurons located in the upper part of the pons; a site well known to be responsible for the "wake up from sleep" effect and whose anatomical location and organic function "overlap" the Pontine center that coordinates the micturition reflex. Besides, the LC has axonal connections with the hypothalamic cells responsible for the production of Vasopressin [12-16].

Motivational therapy should be the initial treatment, using artifices or rewards for the days in which the child does not wet his/her bed. A conditioning treatment may also be used. In this case a sound or vibration alarm warns the child that he/she has urinated. The success rate ranges from $30 \%$ to $60 \%$; however, relapse is quite high when the alarm is removed [17].

The drug-based treatment uses desmopressin, an antidiuretic hormone inhibitor; tricyclic antidepressants, whose function is not quite clear but that appear to have a noradrenergic function; and the anticholinergic ones themselves, among which antimuscarinic oxybutynin is the drug mostly used in the treatment of an overactive bladder. Studies have shown good results from the use of urological physiotherapy in the treatment of urinary incontinence. Urological physiotherapy involves techniques of parasacral or posterior tibial neuromodulation combined with biofeedback $[5,18]$. Neuromodulation consists of transcutaneous electrical stimulation of the sacral roots (S3), whose mechanics has not been clearly elucidated. Clearly there is direct stimulation of the muscle fibers, inhibition of parasympathetic nerves and activation of the sympathetic innervation. The outcome of that would be relaxation of the bladder and inhibition of the detrusor overactivity.

Biofeedback involves training of the pelvic floor muscles that enables the child to be aware of her/his muscle activity, i.e., of its relaxation, contraction and coordination, thus providing greater perineal awareness of the situations that cause the urinary leak $[19,20]$. This paper is the first one of a series aiming to assess the efficacy of the combination of different enuresis treatment modalities. It aimed to compare the efficacy of urological physiotherapy along with parasacral neuromodulation and biofeedback combined with the use of oxybutynin in the treatment of monosymptomatic and no monosymptomatic enuresis.

\section{Materials and Methods}

This paper was approved by the ethics committee of the Regional University of Blumenau and of the Federal University of São Paulo - Escola Paulista de Medicina. Eighty-two (82) children of both genders, with a nocturnal enuresis diagnosis were selected, ages ranging from 5 to 14 years, in the period from January to July 2017. Children with dysfunction of the lower urinary tract of neurological etiology were excluded from the assessment as well as patients presenting with an anatomic anomaly such posterior urethral valve, ureterocele, ectopic ureter, etc.

The children were separated into two groups:

a) Group 1: use of $0.2 \mathrm{mg} / \mathrm{kg}$ oxybutynin every 12 hours.

b) Group 2: use of $0.2 \mathrm{mg} / \mathrm{kg}$ oxybutynin every 12 hours + urological physiotherapy along with neuromodulation and biofeedback.

All the patients were instructed to adopt basic urotherapy: calendars showing the "dry" and "wet" nights; instruction to increase fluid consumption during the day and fluids restriction at night, at least 2 hours before bedtime; micturition every 3 to 4 hours during the day, regardless of the need or want to urinate, and voiding before going to sleep. Such instructions were printed in the voiding diary that was filled out by the parents so as we could verify the treatment adherence at every visit.

For physiotherapy with parasacral neuromodulation, two $3.5 \mathrm{~cm}$ superficial electrodes were applied, one on each side of the sacrum, at the S2 and S3 level, electric energy produced by a generator (Dualpex Uro 961, Quark®, Piracicaba - São Paulo, Brazil). $10 \mathrm{~Hz}$ was the frequency used with an average voltage (interval) of 22.2 (6-42) $\mathrm{mA}$. The intensity was increased to the maximum level tolerated by the child. The electric stimulation was applied 2 days a week, in 20 - 30 min. sessions. The number of sessions varied according to the outcome. Training of the pelvic floor muscle biofeedback consisted of placing two superficial electromyography electrodes on the perineum in 3 and 9 o'clock position, and one on the abdomen, where every micturition was registered by uroflowmetry. Watching the muscle activity on the computer screen, the child was taught to contract and relax the pelvic floor muscles. The biofeedback was carried out once a week. The children had a once a month follow-up, and the final evaluation of the treatment response was made after 12 weeks.

The results were evaluated according to the ICCS [21] standardization: No response: at least $50 \%$ fewer wet nights; partial response: $50 \%$ to $99 \%$ fewer wet nights; complete response: over $99 \%$ fewer wet nights. 
Enuresis episodes were classified as monosymptomatic, when no other symptom was associated, and nonmonosymptomatic, when associated with daytime symptoms (little or very frequent voiding, pollakiuria, urgency, urge incontinence, weak urine stream, intestinal obstipation or fecal incontinence). For statistical analysis the continuous variables were assessed by the Qui-square test. Fisher's exact test was used for comparison of categorical data. The results were considered significant for $\mathrm{p}<0.05$.

\section{Results}

Out of the eighty-two children, forty-nine (59.8\%) were boys and thirty-three $(40.2 \%)$ were girls. All the children were aged between five and fourteen years, of which, thirty-nine (47.6\%) were aged between five and seven years, twenty-seven (32.9\%) were aged between eight and ten years and sixteen (19.5\%) over ten years. As for the enuresis classification, forty-four children had monosymptomatic enuresis and thirty-eight had nonmonosymptomatic enuresis. The family history for nocturnal enuresis was present in $62.6 \%$ of the patients analyzed.

On week twelve, among the children who had no physiotherapy (Group 1), 32.1\% achieved no response to the treatment, $39.3 \%$ achieved partial response and $28.6 \%$ achieved complete response. In the group that had physiotherapy (Group 2) $11.1 \%$ achieved no response, $24.1 \%$ achieved partial response, and $64.8 \%$ achieved complete response. Thus, the children who had physiotherapy and oxybutynin treatment achieved a better result than the children who took the medication alone $(\mathrm{p}=0.005)$ (Table 1).

Table 1: Comparison between treatment with no physiotherapy and fewer wet nights 12 weeks $(p=0.005)$.

\begin{tabular}{|c|c|c|c|c|}
\hline Variables & \multicolumn{2}{|c|}{ Group 1 } & \multicolumn{2}{c|}{ Group 2 } \\
\hline & N & \% & n & $\%$ \\
\hline No response & 9 & $32.10 \%$ & 6 & $11.10 \%$ \\
\hline Partial Response & 11 & $39.30 \%$ & 13 & $24.10 \%$ \\
\hline Complete Response & 8 & $28.60 \%$ & 35 & $64.80 \%$ \\
\hline Total & 28 & $100 \%$ & 54 & $100 \%$ \\
\hline
\end{tabular}

Both groups were also compared in regard to the reduction of wet nights in both the patients with monosymptomatic enuresis and those with nonmonosymptomatic enuresis during the treatment period.

Table 2: Comparison between treatment and fewer wet nights for monosymptomatic enuresis in 12 weeks.

\begin{tabular}{|c|c|c|c|c|}
\hline Variables & \multicolumn{2}{|c|}{ Group 1 } & \multicolumn{2}{c|}{ Group 2 } \\
\hline & N & \% & N & \% \\
\hline No response & 4 & $36.40 \%$ & 5 & $15.10 \%$ \\
\hline Partial Response & 5 & $45.50 \%$ & 5 & $15.10 \%$ \\
\hline Complete Response & 2 & $18.10 \%$ & 23 & $69.80 \%$ \\
\hline Total & 11 & $100 \%$ & 33 & $100 \%$ \\
\hline
\end{tabular}

Out of the patients with monosymptomatic enuresis, $36.4 \%$ achieved no response, $45.5 \%$ achieved partial response and $18.1 \%$ achieved complete response in group 1 . Whereas in group 2, 15.1\% achieved no response, $15.1 \%$ achieved partial response and $69.8 \%$ achieved complete response $(p<0.011)$ (Table 2). Out of the patients with nonmonosymptomatic enuresis, $29.4 \%$ achieved no response, $41.2 \%$ achieved partial response and $29.4 \%$ achieved complete response in group 1. In Group 2, 4.8\% achieved no response, 33.3\% achieved partial response and $61.9 \%$ achieved complete response $(p=0.05)$ (Table 3). The response to the treatment with physiotherapy for monosymptomatic enuresis was compared to that for nonmonosymptomatic enuresis to check whether the efficacy was greater in either of them; however, no difference was found $(\mathrm{p}=0.19)$.

Table 3: Comparison between treatment and fewer wet nights for nonmonosymptomatic enuresis.

\begin{tabular}{|c|c|c|c|c|}
\hline Variables & \multicolumn{2}{|c|}{ Group 1 } & \multicolumn{2}{c|}{ Group 2 } \\
\hline & n & \% & n & \% \\
\hline No response & 5 & 0.294 & 1 & 0.048 \\
\hline Partial Response & 7 & 0.412 & 7 & 0.333 \\
\hline Complete Response & 5 & 0.294 & 13 & 0.619 \\
\hline Total & 17 & 1 & 21 & 1 \\
\hline
\end{tabular}

\section{Discussion}

It has been quite a while since bedwetting is no longer deemed the outcome of a neurosis, whose primary treatment used to be psychotherapy or even no treatment at all. Currently, evidence points at three different mechanisms, all of which may either be present in the same child or each one appears alone: nocturnal polyuria, higher urinary arousal threshold and nocturnal overactivity of the detrusor muscle [6].

The first line treatment is usually referred to as basic urotherapy: restriction of fluids near bedtime, encouragement for bladder emptying approximately every 3 hours, voiding before going to bed [22].

In this paper we advocate that a multiple etiologies condition should be treated by a combination of techniques and/ or medications. Thus, we decided to start a study that would assess the efficacy of the combination of electrostimulation and biofeedback and the use of antimuscarinic oxybutynin, compared to a group of children that were given oxybutynin alone. It was clearly found that the children treated with the combination achieved results that were better than those of the children treated with Oxybutynin alone.

When the results of the children with nonmonosymptomatic enuresis were compared to those presenting with monosymptomatic enuresis no statistically significant difference was found, suggesting that it is very little likely that they would be two different conditions. 
There is evidence that the use of electrostimulation and biofeedback has a positive action in the reduction of the number of wet nights of the children with an overactive bladder and that, in a certain way, all bedwetting children would have, at a higher or smaller degree, detrusor overactivity $[5,18,19,23]$. The study has a few limitations such as the lack of a control group in which the patients would undergo a placebo-based therapy; however, in this study the aim was only to assess the efficacy of the combination as compared to monotherapy.

Other studies comparing different treatment combinations are being planned, seeking the best, or most suitable, combination for those patients that, as it seems, have a locus coeruleus condition and whose treatment deserves to be unified.

\section{Conclusion}

The patients that underwent the combination of physiotherapy with biofeedback and parasacral stimulation plus the use of oxybutynin for 12 weeks achieved a higher cure rate and better partial improvement as compared to the patients in the group that was given oxybutynin alone. Such result was found in patients with both monosymptomatic enuresis and nonmonosymptomatic enuresis.

\section{Acknowledgement}

The authors would like to thank Dr Erika Santos Vieira and Dr Samantha Nagasako Soejima for their invaluable assistance in the preparation of the Manuscipt.

\section{References}

1. Abrams P, Cardozo L, Fall M, Griffiths D, Rosier P, et al. (2003) The standardization of terminology in lower urinary tract function: report from the standardization sub-committee of the International Continence Society. Urology 61(1): 37-49.

2. Kerrebroeck VP, Abrams P, Chaikin D, Donovan J, Fonda D, et al (2002) The standardization of terminology in nocturia: report from the Standardization Sub-Committee of the International Continence Society. Neurourol Urodyn 21(2): 179-183.

3. Van de Walle J, Rittig S, Bauer S (2012) Practical consensus guidelines for the management of enuresis. Eur J Pediatr 171(6): 971-983.

4. Neveus T, Gontard VA, Hoebeke P, Hjälmás K, Bauer S, et al. (2006) The standardization of terminology of lower urinary tract function in children and adolescents: Report from the standardization committee of the international children's continence society. J Urol 176(1): 314324.

5. Lordêlo P, Soares PV, Maciel I, Macedo A, Barroso U (2009) Prospective study of transcutaneous parasacral electrical stimulation for overactive bladder in children: long-term results. J Urol 182(6): 2900-2904.

6. Neveus T (2011) Nocturnal enuresis - Theoretic backgroud and practical guidelines. Pediatr Nephrol 26(8): 1207-1214.
7. Ritting S, Knudsen UB, Nørgaard JP, Pedersen EB, Djurhus JC (1989) Abnormal diurnal rhythm of plasma vasopressin and urinary output in patients with enuresis. Am J Physiol 256(4 Pt 2): F664-671.

8. Rasmussen PV, Kirk J, Borup K, Nørgaard JP, Djurhus JC (1996) Enuresis nocturna can be provoked in normal healthy children by increasing the nocturnal urine output. Scand J Urol 30(1): 57-61.

9. Fonseca EG, Bordallo AP, Garcia PK, Munhoz C, Silva CP (2009) Lower urinary tract symptoms in enuretic and nonenuretic children. J Urol 182(4Suppl): 1978-1983.

10. Nevéus T, Tuvemo T, Läckgren G, Stenberg A (2001) Bladder capacity and renal concentrating ability in enuresis - pathogenic implications. J Urol 165(6 Pt 1): 2022-2025.

11. Wolfish NM, Pivik RT, Busby KA (1997) Elevated sleep arousal thresholds in enuretic boys: clinical implications. Acta Paediatr 86(4): 381-384.

12. Kayama Y, Koyama Y (1998) Brainstem neural mechanisms of sleep and wakefulness. Eur Urol 33(Suppl 3): 12-15.

13. Holstege G, Griffiths D, De Wall H, Dalm E (1986) Anatomical and physiological observations on supraspinal control of bladder and urethral sphincter muscle in the cat. J Comp Neurol 250(4): 449-461.

14. Lightman SL, Todd K, Everitt BJ (1984) Ascending noradrenergic projections from the brainstem: evidence for a major role in the regulation of blood pressure and Vasopressin secretion. Exp Brain Res 55(1): 145-151.

15. Ornitz EM, Russell AT, Hanna GL, Gabikian P, Gehricke JG, et al. (1999) Prepulse inhibition of startle and the neurobiology of primary nocturnal enuresis. Biol Psychiatry 45(11): 1455-1466.

16. Danysz W, Kostowski W, Hauptmann M (1985) Evidence for the locus coeruleus involvement in desipramine action in animal models of depression. Pol J Pharmacol Pharm 37(6): 855-864.

17. Elder J Enuresis and voiding dysfunction. Nelson Textbook of Pediatrics. Kliegman RM, Stanton BF, St Geme JW, Philadelphia, Elsevier 2(543): 2581-2586.e1

18. Quintiliano F, Veiga ML, Moraes M, Cunha C, de Oliveira LF, et al. (2015) Transcutaneous parasacral electrical stimulation vs oxybutinin for the treatment of overactive bladder in children: a randomized clinical trial. J Urol 193(5 Suppl): 1749-1753.

19. Hsu LF, Liao YM, Lai FC, Tsai PS (2016) Beneficial effects of biofeedback-assisted pelvic floor muscle training in patients with urinary incontinence after radical prostatectomy: a systematic review and metaanalysis. Int J Nurs Stud 60: 99-111.

20. Sancak EB, Akbas A, Kurt O, Alan C, Ersay AR (2016) The effectiveness of biofeedback therapy in children with monosymptomatic enuresis resistant to desmopressin treatment. Turk J Urol 42(4): 278-284.

21. 21 ICCS. International Children's Continence Society.

22. Nevéus T, Eggert P, Evans J, Macedo A, Ritting S, et al. (2010) Evaluation and treatment of monosymptomatic enuresis - a standardization document from the Intenational Children's Continence Society. J Urol 183(2): 441-447.

23. Griffiths D, Clarkson B, Tadic SD, Resnick NM (2015) Brain mechanisms underlying urge incontinence and its response to pelvic floor muscle training. J Urol 194(3): 708-715 
(C) This work is licensed under Creative Commons Attribution 4.0 License

DOI: $10.19080 / J O J U N .2019 .06 .555688$

\section{Your next submission with Juniper Publishers} will reach you the below assets

- Quality Editorial service

- Swift Peer Review

- Reprints availability

- E-prints Service

- Manuscript Podcast for convenient understanding

- Global attainment for your research

- Manuscript accessibility in different formats

( Pdf, E-pub, Full Text, Audio)

- Unceasing customer service

Track the below URL for one-step submission https://juniperpublishers.com/online-submission.php 